\title{
A network approach to overcoming barriers to market engagement for SMEs in energy efficiency initiatives such as the Green Deal
}

Juliette M. O’Keeffe, Daniel Gilmour, Edward Simpson

This is the accepted manuscript (C) 2016, Elsevier Licensed under the Creative Commons AttributionNonCommercial-NoDerivatives 4.0 International: http:// creativecommons.org/licenses/by-nc-nd/4.0/

\section{(C) $\oplus \Theta \Theta$}

The published article is available from doi:

http://dx.doi.org/10.1016/j.enpol.2016.08.006 


\title{
A network approach to overcoming barriers to market engagement for SMEs in energy efficiency initiatives such as the Green Deal
}

Juliette M. O'Keeffe ${ }^{\mathrm{a}}$, Daniel Gilmour ${ }^{\mathrm{b},}$ Edward Simpson ${ }^{\mathrm{c}}$

aSchool of Science, Engineering and Technology, Abertay University. Bell Street, Dundee, Scotland, UK, DD1 1HG. j.o'keeffe@abertay.ac.uk

${ }^{\mathrm{b}}$ School of Science, Engineering and Technology, Abertay University. Bell Street, Dundee, Scotland, UK, DD1 1HG. d.gilmour@abertay.ac.uk

'School of Science, Engineering and Technology, Abertay University. Bell Street, Dundee, Scotland, UK, DD1 1HG. e.simpson@abertay.ac.uk

Corresponding author: j.o'keeffe@abertay.ac.uk

\begin{abstract}
The Green Deal (GD) was launched in 2013 by the UK Government as a market-led scheme to encourage uptake of energy efficiency measures in the UK and create green sector jobs. The scheme closed in July 2015 after 30 months due to government concerns over low uptake and industry standards but additional factors potentially contributed to its failure such as poor scheme design and lack of understanding of the customer and supply chain journey. We explore the role of key delivery agents of GD services, specifically SMEs, and we use the LoCal-Net project as a case study to examine the use of networks to identify and reduce barriers to SME market engagement. We find that SMEs experienced multiple barriers to interaction with the GD such as lack of access to information, training, and confusion over delivery of the scheme but benefited from interaction with the network to access information, improve understanding of the scheme, increasing networking opportunities and forming new business models and partnerships to reduce risk. The importance of SMEs as delivery
\end{abstract}


agents and their role in the design of market-led schemes such as the GD are discussed with recommendations for improving SME engagement in green sector initiatives.

\section{Key words}

energy efficiency, green deal, market-led, network, SME

\section{Introduction}

Environmental policy in the UK links improvement of the environment with economic benefit, in line with ecological modernisation theory (Revell 2007). Policy is thus designed to convey economic benefits from taking voluntary actions to reduce environmental impacts. For energy efficiency improvements in the UK, the government has used several mechanisms in recent decades to offer economic incentives to property owners and managers to act voluntarily to reduce energy consumption. These have included the Boiler Scrappage Scheme, Carbon Emissions Reduction Target (CERT) funding, Community Energy Saving Programme (CESP) and other regional and national schemes to achieve national carbon reduction targets (Dowson et al. 2012). CERT and CESP, funded through obligations placed on energy suppliers, resulted in large numbers of properties in the UK receiving free or low cost insulation between 2008 and 2012. The majority of properties being insulated during this period received some level of financial support through these schemes (DECC 2012). Policy makers designed these funding mechanisms to increase demand for energy efficiency measures to be installed in domestic properties and focused largely on quick-win measures (e.g. loft insulation, low energy lighting). Consumers accessed subsidized products directly through retailers, allowing for basic and affordable improvements to be undertaken, and relatively swift reductions in electricity and heating fuel consumption to be achieved. In 2012, the European Commission set an objective of reducing primary energy consumption across the EU by $20 \%$ by 2020 through the EU Energy Efficiency Directive (2012/27/EU) (European Commission 2012). As a result Member States were required to set national targets and 
indicate how these would be achieved, through National Energy Efficiency Action Plans (NEEAPs). The UK NEEAP sets out the UK measures and initiatives that are intended to achieve a $20 \%$ reduction in energy consumption by 2020 based on 2007 levels (DECC 2014a). One of the primary drivers for UK energy reductions in the domestic sector was stated in the UK NEEAP to be a market led scheme, the Green Deal (GD), designed to allow consumers to take up energy efficiency measures at no upfront cost, and potentially create thousands of jobs in the energy efficiency sector. In 2010, the UK Government projected that jobs in the energy efficiency sector could rise from 27,000 to 250,000 within a decade if all households in the UK took up a GD (UK Government 2010).

The GD scheme was introduced by the Department for Energy and Climate Change (DECC) in January 2013, after several months delay. The premise of the GD was to allow consumers to have energy saving measures installed at no up-front cost via a loan paid back through the savings on their energy bill. In order to participate, consumers would seek out a GD Assessor to carry out a property assessment and produce an advice report recommending energy efficiency measures appropriate for the property. To access measures at no cost to the consumer, the assessor would indicate in the report which measures met the "Golden Rule", or provided savings greater than or equal to the payback cost of the measure (including loan interest over a fixed period), based on the household energy consumption and predicted efficiency of the measure. The consumer could then contact a GD Provider to seek out a finance plan and finally commission a certified GD Installer to install the measure(s). A GD payment would be arranged to be paid via energy bills and remain tied to the property until the measure was paid off. Some consumers undertook assessments simply to gain access to cashback schemes, which could be accessed regardless of whether a GD plan was taken up.

In the first year of the scheme, relatively few consumers took up GD plans. Of 129,828 GD assessments lodged, only 1,743 measures were installed through 626 GD plans in 2013 
(DECC 2014b). In the following year the number of assessments increased with an additional 317,489 assessments being lodged, and 7,518 measures installed through 4095 GD plans. Up to the end of June 2015, 128,619 additional assessments had been lodged and 6605 measures installed through 5,278 live GD plans. Despite the government's intention for the GD to be a key driver of reduced domestic energy consumption by 2020 , and to create a substantial number of jobs, this was not achieved. On 23 July 2015, the UK Government announced that no further funding would be made available to the Green Deal Finance Company, the body providing lending to GD projects, citing "low take-up" of the GD and "concerns about industry standards" as reasons for the scheme closure. In addition, the government announced that no further funding releases of cashback through the supporting Green Deal Home Improvement Fund would be made and that the Government would commission an independent review (the Bonfield review) "...to look at standards, consumer protection and enforcement of energy efficiency schemes" (UK Government 2015) in order to identify ways to tackle problems within the supply chain "such as rogue traders, poor quality installations and compliance issues", which the government claimed "caused a real impact on consumers" (DECC 2015). These statements implied that problems with the delivery of the GD by the supply chain caused the closure of the scheme.

Throughout the scheme, some issues related to rogue traders and fraudulent activity had been identified by organisations such as Citizens Advice. In the six months to February 2014, the Citizens Advice Consumer Helpline received 1250 GD related complaints (Citizens Advice 2014). Most of these (70\%) were related to scams or possible scams. While this does indicate that were issue surrounding opportunists using the GD to scam homeowners, it does not necessarily indicate that supply chain practices were to blame for the failure of the scheme closure. The findings of the Bonfield review have yet to be published, but the Committee of Public Accounts reported in 2016 that the key reasons for the GD failure included lack of adequate testing, the over complexity of the process, the bureaucracy, the unattractiveness of the interest rates, the focus on financial incentives rather than comfort 
benefits and lack of action on early warnings about flaws in the design of the scheme. Industry standards were not listed in this report as a primary cause of failure of the scheme.

The findings of the Committee of Public Accounts (2016) indicate that understanding the customer journey and how consumers interact with the supply chain is important in the design of in schemes such as the GD. This paper thus explores specifically the role of the key delivery agents of energy efficiency improvements in the construction sector, with a focus on barriers to market engagement experienced by the SME supply chain in the sector. In this paper we present, as a case study, the approach we took to identify and reduce barriers to low-carbon innovation amongst Scottish SMEs through a European Regional Development Fund and Scottish Government (Scottish Innovative Low Carbon) funded project, LoCal-Net. The aim of the project was to support SMEs to develop innovative products, services and processes leading to carbon emission reductions by accessing networks designed by the LoCal-Net team around low carbon market opportunities where SMEs faced barriers to innovation. We discuss the development and observations of the SME interactions with one of these networks, the Green Deal Scotland network. We present our reflection on the barriers to GD market engagement faced by SMEs as key delivery agents of the GD scheme, and the impact of networks on reducing barriers to innovation and market engagement for construction sector SMEs. These findings lead to an examination of how greater awareness of the complexities of the customer journey and the supply chain journey in delivery of market-led initiatives to deliver policy objectives could improve the design of schemes such as the GD.

\section{Background to SME engagement in the energy efficiency sector}

\subsection{SMEs in the energy efficiency market}


Construction firms involved in repair, maintenance and improvement services dominate the market for home renovations such as services required during energy efficiency upgrades (Killip 2013). The UK construction sector is made up primarily of SMEs. Of the 257,425 construction sector businesses across the UK in 2013, 93\% had less than 10 employees with over $83 \%$ having only $0-4$ employees (ONS 2013). SMEs represent the vast majority of installers of energy efficiency measures, but also represent many of the domestic energy assessors (DEAs) and GD advisors (GDAs). These groups are in direct contact with consumers in the energy efficiency market, and thus they are influential in the uptake of energy efficiency measures in domestic properties and may be the only direct point of contact that consumers have when considering energy efficiency upgrades (Owen et al. 2014). The delivery of energy efficiency measures offered through the GD was thus unavoidably dependent on delivery by SMEs.

Despite the importance of SMEs in the delivery of GD measures, the government's focus of actions to support and encourage the uptake of the GD was largely targeted at homeowners and local authorities. In the promotion of the scheme, the UK and Scottish governments offered consumers financial incentives to take up energy efficiency surveys and measures and provided local authorities with funding to raise awareness and promote the uptake of measures (DECC 2014a). The government expected the market to develop mechanisms for selling GD products and services to consumers. The government also intended for the new financial measures designed into the GD to align better with previous incentives and to help consumers overcome basic financial barriers to energy efficiency improvements by providing upgrades at no upfront cost. The design of the scheme did not however seek to address barriers of lack of information, risk and uncertainty and psychological or sociological barriers that are present within the market (James 2012, NERA 2007, Marchand et al. 2015). The designers of the scheme therefore did not fully consider the customer journey in the uptake of energy efficiency measure, nor did they consider the role of the supply chain or potential barriers that may have existed in the supply chain journey. 


\subsection{Barriers to low carbon innovation for SMEs in the construction sector}

In the construction sector, perceived demand for sustainable buildings and construction methods amongst SME builders has been low, and can limit the incentive for businesses to invest or innovate, in providing services linked to environmental improvements (Revell 2007). The short lived nature of support or incentive schemes can skew the demand for energy efficiency measures, and unless provided at little or no costs, homeowners seem unlikely to prioritise energy efficiency measures over other home improvements (Dowson et al. 2012). Short lived incentive schemes introduce risk and uncertainty for SMEs. SMEs may be required to undertake significant training and recertification in order to deliver specific measures and comply with funding schemes offered to homeowners, but may be excluded from available incentives thus making them less willing to engage in the market (Owen et al. 2014). In order for SMEs to consider innovative approaches to delivery of services in the sector, both incentive and capacity to innovate is required. Innovation by SMEs may be in the form of new techniques or technologies, or could include the development of business models that reduce risks associated with providing services tailored to a specific scheme. Innovation occurs more slowly in the construction sector than in other sectors, with many small firms lacking the resources to innovate independently (Mlecnik 2013). In addition, SMEs in general have reduced access to external resources compared to large firms, have fewer resources to develop innovations internally and may lack some capabilities in specific technical aspects of product or service delivery (Suh and Kim 2012).

\subsection{The use of networks to reduce barriers to eco-innovation}

Business networks have been used successfully in various sectors to support small firm growth by providing access to information and knowledge resources, and creating capacity to innovate (Macpherson and Holt 2007). Firms connected to networks tend to be more 
innovative than unconnected firms, as personal relationships and trust building between businesses helps to lower the risks associated with opportunistic behaviors (Ceci and lubatti 2012). A range of actors from external organisations including public agencies and universities can provide a supporting framework for knowledge transfer to occur through the use of networks. Facilitating the relationships between SMEs and intermediaries, and the using networks in driving eco-innovation can reduce the time and knowledge constraints experienced by SMEs in the innovation processes and increase their capacity to innovate (Klewitz et al. 2012). The use of networks can also provide access to external resources to supplement the firm's existing resources, and intermediaries, either public or private, can assist the networking process. The role of networks in the low carbon sector may be important in the transition to a low carbon economy, with networks providing connection between actors that increases resilience (Parag et al. 2013). Networks could also be important in assisting the supply chain to deliver on schemes such as the GD.

\subsection{Methodology}

In this study we have adopted an action research method where we have sought to identify an effective solution that can reduce barriers to eco-innovation for SMEs through action and reflection, theory and practice whilst engaging with others (Reason and Bradbury, 2001). Using this approach we expect to evaluate if networks can reduce barriers to market engagement for SMEs in schemes such as the GD. This approach follows the third person practice where we worked with practitioners (Bradbury-Huang, 2010) in a relatively decentralised way in real time (Chandler and Torbert, 2003). We use the Green Deal Scotland network to identify and examine the barriers faced by delivery agents (SMEs) of market led schemes designed to achieve environmental improvements. We then evaluate the case study as an intervention to examine whether the use of networks to assist SMEs in overcoming barriers to low carbon innovation is effective. We describe the development of the network in detail and the methods we used to identify areas of opportunity for innovation, 
and to identify barriers to innovation experienced by SMEs. The practitioners we worked with engaged in the experiment, enabling us to reflect on the impact that our intervention had.

\subsection{Project development}

Our project, entitled "LoCal-Net", based at Abertay University, was awarded funding under the European Regional Development Fund (ERDF) Priority 1 (Research and Innovation) with the purpose of helping SMEs overcome barriers to low carbon innovation, including entering new low carbon markets. The two year project was designed to help SMEs transition into low carbon markets through the use of learning alliances, or networks, to build capacity amongst actors to overcome specific barriers. This approach was based upon transitioning tools developed by Duffy and Jefferies (2011). In phase one of the project (visioning), we identified specific low carbon opportunities and barriers faced by SMEs through engagement with small groups of businesses. In phase two we formed networks, around specific themes or barriers with key actors in the network including both SMEs and non-SMEs (e.g. larger firms, training providers). We intended for the networks to help actors gain quicker access to relevant information and identify potential partners or solution providers. In order to measure the success of the networks, the project team measured indicators such as SME participation, job creation, increased turnover for SMEs, and new products, services or processes developed.

\subsection{Implementing the network approach}

\subsubsection{Phase 1: Visioning}

In phase 1 of the LoCal-Net project we organised information and scoping events in partnership with local construction forums, inviting forum members to attend to discuss opportunities or barriers to low carbon innovation in the construction sector, and the 
possibility of using networks to assist innovation amongst SMEs in the sector. These events took place in April and May 2012 with approximately 30 participants attending each event. At each event we introduced the LoCal-Net project aims and led a workshop discussion session in break-out groups during which attendees discussed potential low carbon opportunities for construction sector SMEs and barriers to low carbon innovation. The topics discussed included new build design, refurbishment, micro-renewables, energy management and materials. During the discussions we asked attendees to record their ideas for low carbon innovation opportunities on a workshop handout, along with any perceived or identified threats, barriers or support needs related to these opportunities. We used the responses to initiate discussions within the groups. In each discussion session, a member of the project team recorded the main points that were discussed and additional comments provided by SMEs. At the end of each workshop, the project team brought the groups together to summarise the outcomes of the discussions, and agree themes amongst the attendees for taking forward within the LoCal-Net project.

In addition to the notes recorded during the workshops, at the end of Workshop 1, we asked attendees to record their interest in various themes by scoring these on a feedback form using a 5 point scale ( $1=$ not interested, 5 = extremely interested), and to indicate the barriers to low carbon innovation that they perceived to be most important using a five point scale ( $1=$ not important, $5=$ extremely important). This form was designed prior to the workshop, therefore included anticipated general areas of interest and barriers to innovation, which may have biased attendees towards specific topics or barriers. Attendees were asked to list "other" areas of interest or barriers, in order to identify any that had been missed by the project team. The theme "low carbon new build construction" was scored highest by all attendees (mean score of 5), followed by low carbon refurbishment (including work covered by the GD) (mean score of 4.6) and low carbon materials (mean score of 4.6$)$. The barriers "generating ideas and finding opportunities", "understanding current policies and regulations" and "specific technical barriers" received the highest mean scores of 3.6 for importance by 
the attendees. This feedback form was not collected at Workshop 2 due to miscommunication with the co-organisers of the event, however, based on the information recorded during the discussion sessions at Workshop 2 the project team identified that similar areas of interest, and barriers were identified in both workshops.

The workshops took place approximately six months prior to the expected launch of the GD, and predictably the GD was a topic of discussion at the workshops. During the workshops, SMEs recorded their own comments related to the GD on workshop handouts, and the project team recorded specific comments made during group discussions. Table 1 presents the collated comments provided by SMEs at these workshops that related to barriers to accessing the GD market and the support suggested by SMEs to assist in overcoming the barriers.

Table 1 SME statements of barriers to the Green Deal market and proposed interventions from Workshops 1 and 2.

Barriers to accessing the Green Deal Support that could assist in overcoming market barriers

Workshop 1

- There is a general lack of information for businesses and consumers

- Requirements for training and qualifications are unclear

- Are traditional skills sufficient for low carbon changes to industry?

\section{Workshop 2}

- No information about how the Green Deal will work

- Green Deal upgrades may only go to big companies and if so, how can SMEs compete?

- There are possible issues for listed buildings for energy efficiency upgrades

- Planning rules and policies may be a barrier

- Homeowners are unaware of the scheme, but need practical advice from installers

- $\quad$ The benefits to SMEs are not clear
- Access to improved information on policy, what the GD will mean for SMEs, where is the scheme going?

- Information on the assistance that is available for training
- General information is needed

- Suggestion for a Green Deal network of SMEs to provide a service to rival larger companies

- Could the network provide information on what is the opportunity and what are the barriers, and ways to overcome these? 
At both workshops, some SME attendees stated that lack of information was a primary barrier to pursuing GD opportunities and provision of information could assist in overcoming this barrier. At Workshop 2, SME attendees stated that competition with large companies was a potential barrier, with the suggestion that local cooperative working or networks could help SMEs to overcome this barrier. The project team used the results of the workshop discussions and feedback forms from Workshop 1 to identify the focus of potential networks. The team concluded that SMEs were potentially facing barriers to engagement with the GD market and a network could be used to overcome issues such as "generating ideas and finding opportunities" as well as "understanding current policies and regulations" and the structure and delivery of the scheme.

\subsubsection{Phase 2: Building the Network}

Following the initial discussion workshops, the LoCal-Net team agreed on formation of the Green Deal Scotland network. We assigned a network coordinator to assist in building the network, and to communicate with members to identify the types of interventions that LoCalNet could undertake. The coordinator organised initial network building events in the form of GD information sessions. We sent out invitations to the attendees of the initial construction forum events, along with a wider group of SMEs from LoCal-Net's construction sector database as well as non SMEs and larger businesses involved in the GD. We organised two GD information workshops, held in August 2012 in Dundee and September 2012, in Fife, where LoCal-Net and government representatives presented details of the GD scheme and the plans for promotion and coordination of the GD in Scotland. Each workshop included a session for attendees to ask questions and discuss ideas for building the network, and to suggest the types of support that could be provided by the network. The project team facilitated the events and recorded notes on discussions from each event. The network 
coordinator invited all attendees to fill in a feedback form following the event in order to identify individuals that wanted to join the network, and to determine the aspect(s) of the GD these individuals were currently involved in or were seeking to be involved in.

Based on the key areas of discussion at each event, and the types of barriers to market engagement identified, the LoCal-Net team agreed some key actions that could be taken to assist the SMEs in the network. These included:

- Providing an online repository of information for network members to access with current information on market development, training opportunities, and dates and locations of future networking and information events

- Forming a Linkedln closed group for members to ask questions and interact in an online environment

- Planning future networking sessions and information events to keep the network informed on GD developments and allow for collaboration and knowledge sharing

- Expanding the network to include other industry organisation (in areas such as skills development, accreditation and training)

- Providing network members with a central point of contact (LoCal-Net) to seek information and connections to other parties

The purpose of the interventions listed above was to assist SMEs to access information, and to enable connections to other key actors in the sector in order to reduce barriers to engagement with the GD market. We delivered these actions from October 2012 to the end of the project funding in 2014. The network coordinator populated GD network pages on the LoCal-Net website, with information and links. This included web links to current news items on the GD and funding calls (tenders, research opportunities), downloadable factual and statistical information on monitoring data for the GD, current procedures and guidance for 
GD businesses, downloadable case studies about other businesses and delivery of the scheme elsewhere in the UK, web links to GD related events and training or funding support for training. The network coordinator created a Linkedln closed group and invited network members to join in order to share information and engage in online discussion. SMEs used the group to post news items, pose questions to other SMEs working in the sector, and to seek out partners in different technical areas or geographical locations. We held networking sessions every 3 to 4 months, some of which were small groupings of SMEs (4-5) on GD specific topics, and some of which were larger cross-network events to expand the networking opportunities for members. We also held joint information events with other organisations such as CITB Construction Skills and the Energy Saving Trust.

The following sections present the reflection on the observations on the level of engagement and use of the network by SMEs, the types of barriers experienced by SMEs and the benefits that we observed from the use of the network by SMEs.

\section{Results}

In assessing the impact of using the network to reduce barriers to innovation, we anticipated that increased innovation capacity could be measured by evidence of SME participation in the network, job creation and increased turnover in participating SMEs, and new products, services or processes being developed. The early closure of the GD scheme prevented longer term impacts being assessed, particularly for Green Deal Assessors and in areas such as job creation and turnover. Although this presents us with a challenge in assessing whether the network presented long term benefits to SMEs, we present our reflection on the level of participation amongst SMEs and the feedback from participants on the benefits of engaging with the network. We also reflect on the types of barriers faced by SMEs within the network to GD market engagement, and how this information may be relevant to the design of future schemes. 


\subsection{Level of participation in the network}

Over the duration of the LoCal-Net project, 82 individuals subscribed to the network, of which 69 were SME participants. Sixty-five members joined the online Linkedln group by the end of the project timescale. The participating businesses included SME contractors involved in installation of measures such as glazing, insulation and micro-renewables as well as DEAs. Non-SME participants included members of government organisations, local colleges, and large businesses including large energy providers. Members interacted with the network through small group meetings, networking events, and information sessions as well as accessing online resources. The network coordinator acted as a central point of contact and received requests by phone, email or Linkedln messenger for both general and specific information and to assist with making connections or sign-posting to other sources of support. Twenty-eight members of the group interacted online by posting content or commenting on posts. The network coordinator received requests for information or assistance or responses to website or group postings at least weekly or more frequently.

\subsection{Barriers identified}

The network coordinator compiled information received from network SMEs from event feedback forms, direct communications by email or phone to the network coordinator, and postings to the Linkedln group. This information was used to summarise the main barriers to GD market engagement identified amongst SMEs. The common barriers expressed by SMEs included:

- Uncertainty on the level of market demand (before launch)

- Uncertainty on sustainability of market demand (schemes have been short-lived in the past) 
- Concern over central government commitment to support the scheme

- Lack of a visible coordination body for marketing and promotion

- High costs of retraining and certification

- Confusion on requirements for certification and registration

- High level of paper work and administration required

- Regular changes to specific aspects of the scheme causing confusion

- General lack of awareness (amongst the SMEs, and perceived lack of awareness in the market)

- Uncertainty on how to explain the scheme to customers

- Confusion on the requirements for developing a GD Plan

- Lack of capacity to deliver large projects

- Lack of access to other GD practitioners

Many SMEs communicated to the network coordinator the reluctance to consider business diversification to provide GD services based on the barriers listed above. Some SMEs perceived the costs of re-training and registration to the scheme along with the added administrative burden to outweigh the potential benefits. Other, particularly qualified DEAs, expressed a concern that their market would disappear if they did not retrain to provide GD assessments. There was a fear that their market for environmental performance certificates (EPCs) would be taken up by large national companies able to deliver the full suite of GD services from assessment through to installation. In this respect, some SMEs saw the GD as a potential threat to existing business models, with the changing landscape of the policy environment causing them some uncertainty and worry. Some of these points are supported by results of the Dods Green Deal Dialogue (Dods 2013), based on an engagement process between industry and DECC on the detail of the GD. The report identified concerns specifically related to barriers for SMEs, which included: 
- "Small businesses seeking to participate in the scheme could find themselves marginalised by large Green Deal providers such as supermarkets"

- "Financial impositions, such as promoting the Green Deal to consumers, could also make the Green Deal less attractive to smaller firms"

SMEs raised these concerns, along with concerns about consumer uptake and public awareness, at SME roundtable meetings with DECC prior to the launch of the GD (Dods 2013). After the launch of the scheme, the Energy and Climate Change Committee (2014) reported to the House of Commons some key concerns and early warnings related to the poor performance of the GD scheme. The concerns that related to the supply chain included the lack of engagement between consumers and the market and poor promotion of the GD amongst consumers. The Committee noted that:

a combination "of financial, communication and behavioural barriers has meant potential customers and partners have been disillusioned and alienated. It is imperative that these barriers are understood and addressed if the scheme is to move forward' (Energy and Climate Change Committee 2014).

\subsection{Partnership working}

The LoCal-Net team observed partnership working between firms that resulted from their interactions with the network. GD assessors and installers who met at LoCal-Net events developed working relationships between each other as did installers of varying technologies such that a more complete service could be offered to potential customers. An example of this was a partnership that was initiated between an external wall insulation specialist and an internal wall insulation specialist to work together to provide a more comprehensive service. Neither firm wished to pursue additional training and incur the costs associated with certification for new measures, although they had indications from customers that there was 
a demand for combined measures to be delivered. Very few SMEs are able to deliver all GD services, with most SMEs specialising in one, or a few, areas only.

SME members of the network explored the idea of partnership working and leveraging the capacity of a network as a basis for small firms and sole traders to collaborate in order to increase competitiveness. As a result of interaction with the network, two groups of businesses emerged to form cooperatives. The cooperative model was chosen in order to allow micro businesses and sole traders to combine capacity to tender for large GD or Energy Company Obligation (ECO) projects, such as local authority or housing association contracts. Businesses identified efficiencies by working together such as eliminating the need for each sole trader or SME to become a GD Advice Organisation (GDAO) in order to lodge reports, and to offer services over a larger geographical area or more diverse clientele. This reduced some risk of engaging with the market by extending capacity through the cooperative to diversify.

SMEs also used the network to access public agencies and officials. Representatives from local councils and the Scottish Government attended events, and SMEs engaged with them directly. On separate occasions, the network coordinator and a group of three SMEs from the network arranged to meet with elected officials (at local authority and UK level) to discuss how the government could assist in raising awareness of the GD and support SMEs to communicate with the public. Unfortunately these meetings did not lead to the officials taking any actions to support the SMEs.

\subsection{Assessing the effectiveness of networks}

The network coordinator sought to gain feedback from network SMEs on the impact of working with networks on reducing barriers to engagement in the GD market. The network coordinator issued a short online survey to network SMEs by email and through posting to 
the Linkedln closed group. The survey link was also cross-posted to the Scottish Energy Saving Trust (EST) Green Deal Installers Network in 2014, where many members of the LoCal-Net network were also subscribers. Only eleven SMEs replied to the survey. Of these, respondents were either GD installers or GD advisors with some involved in multiple GD services. The low response rate was disappointing, but may be reflective of the proportion of actors that actively engaged in network activities. Although there were 69 SME members subscribed to the Green Deal Scotland network, less than half of these interacted regularly through attendance at events or through direct communication with the network coordinator. The survey responses indicate that all respondents apart from one had attended a network event, with all but two of these attending at least two events. The responses to the survey are detailed below:

\subsubsection{Involvement in the energy efficiency products or services market before the Green}

Deal launch:

Two businesses stated they had not been involved in this sector prior to the launch of the GD with $91-100 \%$ of their business turnover now in the energy efficiency market. One business indicated a small proportion of business turnover (11-20\%) had been in the energy efficiency sector prior to the launch of the GD and since the launch of the GD had grown to $61-70 \%$. Of the other eight SMEs, six indicated no change in their activity in this sector, with energy efficiency activities maintaining a constant share of their turnover since the introduction of the GD. Two SMEs indicated that they had decreased their activity in the energy efficiency market; one indicated a drop from $91-100 \%$ to $51-60 \%$ and the other from $91-100 \%$ to $11-20 \%$. This indicated a significant reduction in turnover related to energy efficiency work since the introduction of the GD for these businesses.

\subsubsection{Barriers experienced:}


Six of the eleven businesses surveyed indicated that they had faced business barriers since the introduction of the GD. The types of barriers listed by respondents in the survey replies included the following:

- Increased bureaucratic burden

- Perceived lack of return for the amount of effort required

- Gaining recognition as an assessor

- Technical issues relating to accessing databases and lodging reports and lack of training on the use of new systems

- Slow payments on ECO related work

- High costs of certification and training

- Lack of local access to certification and training

- Lack of access to impartial and informed assistance

- Perception that time and resources were wasted pursuing training and accreditation that has not been necessary

- Finance and the movement of GD plans

- Demise of certain funding aspects such as the ECO Boiler Scheme harming installers

- Requirement for upfront payment for elements of the cashback scheme being a disincentive for customers

These responses are broadly similar to the barriers identified in Phase 1 of the LoCal-Net project, and collated by the network coordinator (4.2) but also include specific barriers related to aspects of the GD that emerged since the launch, such as issues related to payments and the demise of certain aspects of the scheme. The results of the survey show some similarities with DECC's UK wide research into the GD supply chain (DECC 2014c), which reported evidence that a lack of information was a barrier for some suppliers, along 
with the complexity and time taken to complete the certification process. Qualitative interviews with suppliers carried out by DECC identified a demand for regular updates, signposting, and suggestions for "a support 'network' that they could utilise" for accessing information.

\subsubsection{Network benefits:}

Although five of the businesses surveyed by LoCal-Net indicated they had experienced no barriers, all but one respondent indicated that they had experienced benefits from participation in GD networks or attendance at training or information events. The businesses related more benefits to interaction with the networks as opposed to just attendance at an event. This suggests that the network provides more than just information for SMEs, and that the value of the network extends beyond remote information sharing.

The types of benefits scored most often as a result of network interaction included:

- Gained information that I could pass along to customers (5 responses)

- Identified new business leads (5 responses)

The next most commonly scored benefits as a result of network interaction included:

- Identified business partners (3 responses)

- Gained a greater understanding of the market (3 responses)

- Became better informed on aspects of GD certification (3 responses)

The most commonly cited benefit from attendance at an event was:

- Became better informed on aspects of GD certification (4 responses) 
Respondents provided further comments on additional benefits they experienced as a result of their interaction with networks or attendance at events. The use of Linkedln was mentioned by two respondents as being beneficial:

- 'Linked-In I find helpful as people will post or comment giving and hearing advice that can match our business"

- "I found at least with Linked-In I could see what others were doing"

Connecting with other businesses in the sector also appeared to be a benefit, sharing views on the delivery of the scheme and the challenges being faced by other SMEs. One SME commented that:

- "Industry experiences and views/opinions assisted in the decision making processes"

Respondents provided additional comments on the types of support that could assist them. The types of support listed included:

- Sharing of market information

- Reducing some of the negativity around the GD

- Assisting in reducing time constraints and paperwork barriers

- Regional access to awareness events, training and certification, which are currently lacking in areas such as the Highlands.

- Specific information sessions on [for example] locating specific postcode areas for funding.

- Assisting SMEs in gaining access to and communication with GD Providers 
SMEs also mentioned frustration at certain aspects of the scheme such as the need for homeowners to obtain three quotes for access to cashback creating extra work for SMEs that did not always translate into new business, and the time and effort required in assisting customers in claiming cashback post-installation. Contradictory information and advice from the Energy Saving Trust was also listed as a source of frustration and therefore a central point of consistent and current information could be beneficial.

\section{Discussion}

The make-up of the energy efficiency sector in the UK suggests that the role of SMEs in schemes such as the GD is significant in the delivery of market-led policy interventions that require homeowners to engage in domestic property improvements. Based on government and industry led reviews, and the observations of the LoCal-Net project, we find that SMEs have faced barriers to engagement in this market. These have included general business barriers such as access to information and training and competition, as well as those that are specific to this scheme such as the framework for financing GD measures, and promotion of the scheme. The network approach we applied through LoCal-Net was effective in identifying the key barriers faced by SMEs, and also highlighting flaws in the scheme. We found that the network approach was effective in reducing some barriers to market engagement by SMEs. Positive effects included improved access to information, awareness of funded training opportunities, introductions to other SMEs and organisations involved in the GD with opportunities for pooling resources, access to experts, and learning from others experience of attaining certification or delivering GD services. Participants also experienced benefits in the form of new business models and modes of working being developed, specifically the development of cooperatives. These results support the proposed benefits of networks described elsewhere by Ceci and lubatti (2012), who suggest that connected firms can build innovation capacity by building trust between firms, and reducing the opportunity risks associated with innovation, and results of van der Vleuten et al. (2013), who identified 
that rural energy entrepreneurs can learn faster through peer-to-peer learning than top down approaches.

For the network members that joined online and accessed information or resources remotely, it is difficult to assess whether the network provided any benefits. Many of the benefits of networks described in the literature are derived from the personal connections and relationships that form between actors in the networks. The survey was intended to assess impacts for all members, both those that actively engaged, and those that were remote members. All but one of the businesses that replied to the online survey had attended events in-person and most of the respondents had interacted multiple times, and in many ways with the network (online and in-person), therefore the impact on members interacting only with online resource has not been fully assessed. The LoCal-Net project was open to members from across Scotland but most activities tended to be localised in the Tayside and Fife regions. Interaction with SMEs across the central belt and the Highlands was possible through the Linkedln group and through provision of online resources but the observed benefits of network engagement appeared to be experienced by the SMEs that interacted in-person with the network the most. If the network had continued, hosting of networking events and information sessions in other regions, such as the Highlands, may have assisted more remote members to derive benefits from the network.

We cannot determine, from the results of the survey, how well the remote members used the online network resources for information purposes only, but it was observed that many of the individuals that joined the network never attended an event, interacted in the online group or made contact with the network coordinator; therefore it would be assumed they joined for the purpose of accessing information, and receiving updates. We did not determine if or how they acted on this information. Some businesses may have used the online resources to observe the progress of the GD and assess the viability of the scheme in the longer term. In network events held early on in the project, some attendees indicate a reluctance to pursue 
entry into the GD market. Firms such as these may have accessed information provided by the network, but decided, based on the information provided, that entry into the market was not in their business interest. The fact that firms chose not to engage with the market may have indicated a positive result from the firm's perspective, given the early closure of the GD scheme. We did not determine the proportion of SMEs that may have considered entry into the GD market but decided not to pursue this due to information provided by the network. This may have been an interesting area for further investigation, particularly to assess how SMEs use networks to reduce the risks of business diversification.

From our observation of the SME interactions within the network, we found that the SMEs used information and networking opportunities to assist their decision making. We also found that SMEs used collaborations within the network to reduce risk in engaging with the market. From the feedback we received from SMEs before the GD began, and while the GD was in operation, we find that the barriers identified by SMEs within the LoCal-Net project mirror many of the flaws in the design of the scheme that were identified by DECC early in the development of the scheme (DECC 2014c, Dods 2013) as well as barriers experienced during the delivery of the scheme as found in the Energy and Climate Change Committee report (2014) related to the interaction of the customer with the scheme. Difficulties surrounding the interpretation and application of the Golden Rule, the need for practitioners to explain complex financial arrangements and cashback schemes and the presence of multiple levels of administration and actors within the GD process provided barriers in both the customer journey and the supply chain journey. Van der Vleuten et al. (2013) observed that activities within the energy sector should be tailored to the capacity of market to adapt, particularly the local private sector active in this market. The ability of SMEs to effectively create a market for uptake of GD products and services was perhaps taken for granted by the designers of the scheme. In the Committee of Public Accounts report (2016) reviewing reasons for 
the failure of the GD, oral evidence supports the need to be aware of the needs of the supply chain. For example, one respondent in the report identifies:

"..the importance of working with the supply chain on some of these very difficult practical construction activities...You need to build up skills and a pipeline...”.

Another respondent states:

"What we have not mentioned today is the supply chain. Since the beginning of obligations, we have had stop-start breaks between each scheme. I think it is absolutely essential that you provide this market, as much as you do the generation market, with long-term certainty for the supply chain and for industry to invest in how they will solve some of these problems. Get innovation flowing and support it."

Recommendations within the report call for greater testing of policy decisions, and evaluation of stakeholder views including a wide range of consumer groups as well as supply chain representatives and industry groups. These recommendations support the findings of our study that supply chain interaction with consumers is an important feature in schemes designed to encourage individual homeowners to take actions within their properties. A greater understanding of the supply chain journey for SMEs in particular and how SMEs innovate could assist policy makers in more effective design of schemes. Within the LoCal-Net network, we identified many of the same barriers as identified in the Committee reports, indicating that networks could be used more effectively by policy makers in both the design of scheme such as the GD, but also in monitoring of progress, uptake, and identification of difficulties throughout the delivery of the scheme. In addition, networks could assist SMEs in interacting with future schemes by reducing relative risks of doing so, 
particularly when many SMEs may be sceptical about the viability of future schemes given the failure of the GD.

\subsection{Conclusions and policy implications}

The application of ecological modernisation theory to environmental aspects of UK energy policy favours the use of market based incentives and voluntary mechanisms to stimulate the improvement in energy efficiency of the UK housing stock. The GD is an example of this in practice, and other schemes like this are likely to emerge in the future. Energy efficiency schemes could be expected to provide a cost efficient means of meeting future energy needs by reducing the overall demand. The GD however, has been costly to the tax payer, while resulting in minimal reduction of energy demand across the country. In order for energy efficiency schemes to be effective, individual consumers and households are required to take action, and due to the nature of the home-improvement sector in the UK, this undoubtedly requires the input of the construction section, and specifically construction sector SMEs.

Evaluation of the causes of failure of the GD has identified a number of weaknesses, specifically linked to scheme design and these indicate a poor understanding of the customer journey but also the supply chain journey. The Government's initial announcement of the closure of the GD seemed to imply that poor standards within the industry were a cause of the scheme failure however failings in industry standards may simply be a casualty of poor scheme design rather than a cause of its failure. It is known that the supply chain in the home improvement sector is largely made up by SMEs, and the sector is traditionally less equipped to innovate that some other sectors. The LoCal-Net project identified a number of areas where SMEs faced barriers to innovation in order to engage with the GD. Where a scheme such as the GD requires the direct interaction of the SME supply chain with the consumer for its success, the importance of supporting this link should not be 
overlooked. Understanding the consumer journey in the uptake of energy efficiency measures and interaction with the supply chain is thus important to preventing failure of schemes such as the GD.

To date, support to SMEs within the energy efficiency sector has been minimal, with policy makers continuing to focus promotion, funding support and information provision on consumers, while neglecting to address the role of delivery agents of schemes. The 2014 Energy and Climate Change Committee report identified areas for improvement yet these were not taken into account. SMEs represent a critical link between government policy objectives and uptake of measures by the market. The importance of this group in delivery of the GD may have been underestimated by policy makers thus both the customer journey as well as the supply chain journey deserves further study in the design of future schemes, and actions taken to reduce barriers to delivery. The interaction of policy makers with SME networks throughout the design and delivery of schemes such as the GD could be a valuable tool to identify potential weaknesses in the scheme early, and to work with the delivery agents to design measures to overcome these. The continued use of networks throughout the delivery of schemes could help to reduce barriers to market growth, encourage SME involvement by reducing their risk of participation in the market, as well as provide a mechanism for continual feedback of information to policy makers.

\section{Acknowledgements}

The authors would like to thank The Scottish Government (Scottish Innovative Low Carbon fund) and the European Regional Development Fund for funding the LoCal-Net project. The authors would also like to acknowledge the SME survey respondents and participants in the LoCal-Net networks.

\section{References}


Bradbury-Huang, H. 2010. What is good action research? Why the resurgent interest? Action Research. 8(1), 93-109.

Ceci, F., lubatti, D., 2012. Personal relationships and innovation diffusion in SME networks: A content analysis approach. Research Policy. 41, 565-579.

Chandler, D., Torbert, B. 2003. Transforming inquiry and action: interweaving 27 flavours of action research, Action Research. 1(2), 133-152.

Citizens Advice. 2014. "Scammers cashing-in on Green Deal".

https://www.citizensadvice.org.uk/about-us/how-citizens-advice-works/media/pressreleases/scammers-cashing-in-on-green-deal/ (accessed 28.07.16)

Committee of Public Accounts. 2016. Household energy efficiency measures (HC125). London: House of Commons.

Department of Energy and Climate Change (DECC). 2012. "Statistical release: estimates of home insulation levels in Great Britain - October 2012".

https://www.gov.uk/government/statistical-data-sets/estimates-of-home-insulation-levels-ingreat-britain · (accessed 5.8.15).

Department of Energy and Climate Change (DECC). 2014a. "UK National Energy Efficiency Action Plan".

https://www.gov.uk/government/uploads/system/uploads/attachment data/file/307993/uk na tional energy efficiency action plan.pdf. (accessed 30.07.14).

Department of Energy and Climate Change (DECC). 2014b. "Domestic Green Deal and Energy Company Obligation in Great Britain, Monthly Report. July 2015". 
https://www.gov.uk/government/uploads/system/uploads/attachment data/file/447263/OFFI CIAL SENSITIVE Monthly Statistical Release - GD ECO in GB July15 FINAL.pdf. (accessed 04.08.15).

Department of Energy and Climate Change (DECC). 2014c. "Research into the Green Deal and ECO Programme Supply Chain". https://www.gov.uk/government/publications/researchinto-the-green-deal-and-eco-programme-supply-chain. (accessed 04.08.15).

Department of Energy and Climate Change (DECC). 2015. Bonfield review terms of reference. https://www.gov.uk/government/publications/bonfield-review-terms-of-reference (accessed 28.07.16).

Dods. 2013. One month in: making the Green Deal work Report 2013. Dods Green Deal Dialogue: Dods Parliamentary Communications Ltd. http://www.ggf.org.uk/publication/one month in making the green deal work. (accessed 03.08.13).

Dowson, M., Poole, A., Harrison, D., Susman, G., 2012. Domestic UK retrofit challenge: Barriers, incentives and current performance leading into the Green Deal. Energy Policy. 50, 294-305.

Duffy, A., Jefferies, C., 2011. The SWITCH Transition Manual. Dundee: University of Abertay Dundee.

Energy and Climate Change Committee. 2014. The Green Deal: watching brief (part 2) HC 348 [INCORPORATING HC 1111, SESSION 2013-14]. London: The Stationery Office Limited.

European Commission. 2012. "Directive 2012/27/EU of the European Parliament and of the Council of 25 October 2012 on energy efficiency". http://eur- 
lex.europa.eu/LexUriServ/LexUriServ.do?uri=OJ:L:2012:315:0001:0056:EN:PDF. (accessed 30.07.2014).

James, P. 2012. Overcoming barriers to low carbon dwellings: The need for innovative models of finance and service-provision. Environmental Development. 2, 6-17.

Killip, G. 2013. "Products, practices and processes: exploring the innovation potential for low-carbon housing refurbishment among small and medium-sized enterprises (SMEs) in the UK construction industry". Energy Policy. 62, 522-530.

Klewitz, J., Zeyen, A., Hansen, E., 2012. Intermediaries driving eco-innovation in SMEs: a qualitative investigation. European Journal of Innovation Management. 15(4), 442-467.

Macpherson, A., Holt, R., 2007. Knowledge, learning and small firm growth: A systematic review of the evidence. Research Policy. 36, 172-192.

Marchand, R.D., Lenny Koh, S.C., Morris, J., 2015. Delivering energy efficiency and carbon reduction schemes in England: Lessons from Green Deal Pioneer Places. Energy Policy. 84, 96-106.

Mlecnik, E. 2013. Opportunities for supplier-led systemic innovation in highly energy-efficient housing. J. of Cleaner Production. 56, 103-111.

NERA. 2007. Evaluation of Supplier Obligation Policy Options: Report for DTI and Defra. London: NERA Economic Consulting. http://www.nera.com/67 5235.htm. (accessed 01.08.14). 
Office of National Statistics (ONS). 2013. "UK Business: Activity, size and location - 2013". http://www.ons.gov.uk/ons/rel/bus-register/uk-business/2013/index.html. (accessed 29.07.14).

Owen, A., Mitchell, G., Gouldson, A., 2014. Unseen influence - The role of low carbon retrofit advisers and installers in the adoption and use of domestic energy technology. Energy Policy. 73, 169-179.

Parag, Y., Hamilton, J., White, V., Hogan, B., 2013. Network approach for local and community governance of energy: The case of Oxfordshire. Energy Policy. 62, 1064-1077.

Reason, P., Bradbury, H. (eds.). 2001. Handbook of action research: Participative inquiry and practice. London: Sage Publications.

Revell, A. 2007. The ecological modernisation of SMEs in the UK's construction industry. Geoforum. 38, 114-126.

Suh, Y. and Kim, M-S., 2012. Effects of SME collaboration on R\&D in the service sector in open innovation. Innovation: Management, policy and practice. 14(3), 349-362.

UK Government. 2010 "Green Deal to create green jobs".

https://www.gov.uk/government/news/green-deal-to-create-green-jobs (accessed 04.08.15).

UK Government. 2015. "Green Deal Finance Company funding to end". https://www.gov.uk/government/news/green-deal-finance-company-funding-to-end (accessed 04.08.15). 
Van der Vleuten, D. Stam, N., van der Plas, R.-J. 2013. Putting rural energy access projects into perspective: What lessons are relevant? Energy Policy. 61, 1071-1078 